\title{
Rapid Diagnosis of Highly Pathogenic Clinical Strains of Yersinia Pseudotuberculosis Using PCR and Preservation of $70 \mathrm{Kbp}$ Virulence Plasmid
}

\author{
Mahmoud Mohamed Mohamed Zaky \\ Botany department, Faculty of science at Port-Said, Suez Canal University, Egypt \\ E-mail: Zakymahmoud@yahoo.co.uk
}

Received: August 28, 2012 Accepted: September 11, 2012

doi:10.5296/jbls.v4i1.2543 URL: http://dx.doi.org/10.5296/jbls.v4i1.2543

\begin{abstract}
Clinical strains of Yersinia.pseudotuberculosis were screened for $70 \mathrm{Kbp}$ virulence plasmids it was found only $20 \%$ carrying $70 \mathrm{Kbp}$ plasmid, when subjected to different concentrations of Naledixin for development of mutant strains , plasmids were lost from one strain Yersinia pseudotuberculosis IP3295, which leaded to the modification of L.B medium into human blood (H.B) L.B medium as culture medium for Yersinia pseudotuberculosis .Yersinia pseudotuberculosis IP3295 showed 70Kbp virulence plasmid with additional small plasmids which proves the incorporation of plasmids with chromosomal DNA and similarity with Yersinia pestis. All strains of Yersinia pseudotuberculosis harboring virulence plasmids were detected for FyuA and Irp2 genes of the High pathogenicity island using PCR. And it was found that all plasmid harboring strains contains high Pathogenicity Island.
\end{abstract}

Keywords: Yersinia pseudotuberculosis, High pathogenecity island, 70Kbp virulence plasmid

\section{Introduction}

Yersinia spp. are gram-negative, facultative rods that are motile when isolated from environment but become non-motile in mammalian host. Three species of Yersinia cause disease in humans: Yersinia enterocolitica, Yersinia pseudotuberculosis, and Yersinia pestis. These species differ considerably in invasiveness. Y. enterocolitica and Y. pseudotuberculosis can cross the gastrointestinal mucosa to infect underlying tissue, but infections usually remain localized in the sub-mucosal area. Y. pestis is injected into the body by an insect bite and thus does not have to penetrate a body surface on its own, but once inside the body, it spreads rapidly and causes a systemic infection (Mingrone and Fantasia, 1988; Cornelis, 2002). 
Infections due to $Y$. enterocolitica and $Y$. pseudotuberculosis are acquired by ingestion of Contaminated food or water. Both of these species are ubiquitous in the environment and infect a variety of wild and domestic animals as well as humans. $Y$. enterocolitica is a common cause of human disease, whereas $Y$. pseudotuberculosis is primarily an animal pathogen that only occasionally causes disease in humans.

In recent years, $Y$. enterocolitica infections have been particularly common among children, And outbreaks have occurred in day-care centers and schools. Symptoms of $Y$. enterocolitica Infections vary from a mild form of the disease, characterized by diarrhea and abdominal pain, To a more severe form, characterized by fever and abdominal pain so severe that it can be Mistaken for appendicitis. Only a relatively small number of $Y$. enterocolitica strains cause disease. These strains are serogrouped using an $\mathrm{O} / \mathrm{H}$ type of system similar to the one used to classify strains of E. coli. The type of disease caused by $Y$. pseudotuberculosis except that diarrhea is usually not a symptom. $Y$. pseudotuberculosis infections are more likely than $Y$. enterocolitica infections to become systemic symptoms of systemic infection are those generally associated with endotoxemia (fever, chills, weight loss, and shock).

$Y$. enterocolitica and $Y$. pseudotuberculosis both have an affinity for Payer's patches and probably transit the mucosa through $\mathrm{M}$ cells. Once they reach the underlying tissue, they enter the mesenteric lymph nodes (the nodes that drain the tissue around the intestine) and multiply there. The bacteria provoke an inflammatory response that is responsible for the abdominal pain.

Both $Y$. enterocolitica and $Y$. pseudotuberculosis are killed by (PMNs), thus the bacteria can multiply in tissue and blood only as long as they can avoid being ingested by (PMNs).

In some people, $Y$. enterocolitica gastrointestinal infections are followed by arthritis of the peripheral joints, which develops 2 to 6 weeks after the intestinal infection has cleared. This arthritis is called reactive arthritis; because it is thought to be caused by $\mathrm{T}$ cells and / or antibodies elicited by antigens that cross-react with host antigen, not by bacterial infection of the joints. Reactive arthritis is seen commonly in people with histocompatibility antigen HLA-B27. Several groups have reported antibodies to bacterial surface antigen that cross-react with human B27, a protein that is exposed on the surface of the host cells. Thus it is possible that fragments of bacteria released during the infection induce antibodies that remain in circulation after the bacteria have cleared. These antibodies bind to B27 triggering a complement-mediated inflammatory response. Alternatively (or additionally) $\mathrm{T}$ cells that recognize B27 could attack host cells (Fukushima et al , 2001; Denecker et al., 2002; Hayashidani et al., 2002; Juris et al., 2002).

\section{Materials and Methods}

\subsection{Bacterial Strains}

20 clinical Strains of Yersinia pseudotuberculosis were gifted by medical microbiology Institute Munich University, Germany. strains were given on L.B and blood agar media for refreshment, and 1.B media with antibiotics such as Nalidexin 


\subsection{Isolation of Plasmid}

Plasmid DNA for large and small Plasmid preparations was extracted by alkaline Lysis method. (Maniatis, 1982)

Nalidexin mutation.

Wild type strains were subjected to different gradients to Nalidexin to reach the consentration $30 \mu$ gLL Naledixin resistance. Hen clones were grown on Nalidexine containing L.B. medium. (Zaky 2004).

\subsection{Preservation of Virulence Plasmids}

$5 \%$ fresh human blood was added to the L.B medium, and poured into plates containing Naledixin. With different concentrations, the strains first grown on the minimal concentration, and incubated in $37^{\circ} \mathrm{C}$, then harvested with spatula after addition of amount of fresh sterile L.B.medium, and then transferred into the next concentration plates and so on until reached $30^{\circ} \mu \mathrm{g} / \mathrm{g}$.

\section{PCR.}

Different sets of primers used for PCR amplification were synthesized by Carl Roth (Karlsruhe, Germany).PCR amplifications were performed in an automated thermal cycler (TRIO Thrmoblock; Biometra, Goetingen, Germany) as described by Saiki et al. with TagI polymerase and different pairs of oligonucleotide primers. The initial denaturation step $\left(94^{\circ} \mathrm{C}\right.$, $5 \mathrm{~min}$ ) was followed by 35 cycles of denaturation $\left(94^{\circ} \mathrm{C}, 1 \mathrm{~min}\right)$, annealing (at the annealing temperature $\mathrm{Tm}, 1 \mathrm{~min})$, and extension $\left(72^{\circ} \mathrm{C}, 1 \mathrm{~min}\right)$, with one final extension step $\left(72^{\circ} \mathrm{C}, 8\right.$ $\mathrm{min})$. The sequences of the forward (FP) and reverse (RP) primers used for PCR reactions, the size of the amplified fragment (S), and Tm were as follows: (i) irp2 (FP), 5'AAGGATTCGCTGTTACCGGAC-3' irp2 (RP), 5'-TCGTCGGGCAGCGTTTCTTCT-3'(S, 280bp; Tm, 61 C);(ii)irp-P242(FP),5'-AAGGATTCGCTGTTACCGGAC-3' irp2-505 (RP), 5'-TCGTCGGGCAGCGTTTCTTCT-3'(S, 264 bp; Tm, 58C); (iii) fyuA(FP), 5'- GCGAC GGGAAGCGATTTA-3' fyuA (RP), 5'- CGCAGTAGGCACGATGTTGTA-3' (S,780bp;Tm 60C);(iv) hmsR (FP) 5'- TAAAGAAAGACCCCACCAATC-3' hmsR (RP), 5'ATCATCGGCATCAAGCAAATC-3'(S, 730 bp; $\mathrm{Tm}, 56 \quad \mathrm{C} ; \quad$ entF (FP), 5'TATCAGCGTTATCACCATTTG-3' entF (RP), 5' - CCAGTTCCGGCAGCGTTTCTT-3' (S, $511 \mathrm{bp}$; Tm, $55 \mathrm{C}$ ); and Ec-chrom (FP), 5'- TTTATTCCGTTGCGTGAGGTT-3', HPI-5end (RP), 5' - TAGGATACCTTCACGCTGCTGTCGCGC-3' (S, 900 bp; Tm 52 C).

intB irp9 irp8irp7 irp6 ybtA irp2
Figure1. Structure of HPI in Yesinia pseudotuberculosis and Yesinia pestis (Kaper and
Hacker, 1999).




\section{Macrothink}

\section{Results}

\subsection{Screening of $70 \mathrm{Kbp}$ Virulence Plasmid}

20 clinical strains of Yersinia pseudotuberculosis were screened for virulence plasmids, and only 5 strains harboring virulence plasmids, and after treatment with naledixin to be naledixin mutants, still harbouring the $70 \mathrm{Kbp}$ virulence plasmids.

Table 1. Clinical strains of Yersinia pseudotuberculosis harbouring 70kbp virulence plasmids and high pathogenicity island.

\begin{tabular}{|c|c|c|c|c|}
\hline No. & Strain & Type & $\begin{array}{c}70 \mathrm{kbp} \\
\text { virulence } \\
\text { plasmid }\end{array}$ & $\begin{array}{c}\text { High } \\
\text { pathogenicity } \\
\text { island }\end{array}$ \\
\hline 1 & Yersinia pseudotuberculosis & I & & \\
\hline 2 & Yersinia pseudotuberculosis & I & $+\mathrm{ve}$ & $+\mathrm{ve}$ \\
\hline 3 & Yersinia pseudotuberculosis & H260/91Ib & & \\
\hline 4 & Yersinia pseudotuberculosis & H47/91C Ia & & \\
\hline 5 & Yersinia pseudotuberculosis & H268/91 & & \\
\hline 6 & Yersinia pseudotuberculosis & H191/91 IA & $+\mathrm{ve}$ & $+\mathrm{Ve}$ \\
\hline 7 & Yersinia pseudotuberculosis & O1A(252) & $+\mathrm{ve}$ & $+\mathrm{ve}$ \\
\hline 8 & Yersinia pseudotuberculosis & IA & & \\
\hline 9 & Yersinia pseudotuberculosis & I & & \\
\hline 10 & Yersinia pseudotuberculosis & I & & \\
\hline 11 & Yersinia pseudotuberculosis & IA & & $+\mathrm{ve}$ \\
\hline 12 & Yersinia pseudotuberculosis & IH 370-36/88 & $+\mathrm{ve}$ & \\
\hline 13 & Yersinia pseudotuberculosis & IH-346-36/88 & & \\
\hline 14 & Yersinia pseudotuberculosis & IB & & $+\mathrm{ve}$ \\
\hline 15 & Yersinia pseudotuberculosis & IB & & $+\mathrm{ve}$ \\
\hline 16 & Yersinia pseudotuberculosis & IP 3295 & $+\mathrm{ve}$ & \\
\hline 17 & Yersinia pseudotuberculosis & IA & & \\
\hline 18 & Yersinia pseudotuberculosis & IA & & \\
\hline 19 & Yersinia pseudotuberculosis & O1A 26/8 & $+\mathrm{ve}$ & \\
\hline 20 & Yersinia pseudotuberculosis & I & & \\
\hline
\end{tabular}




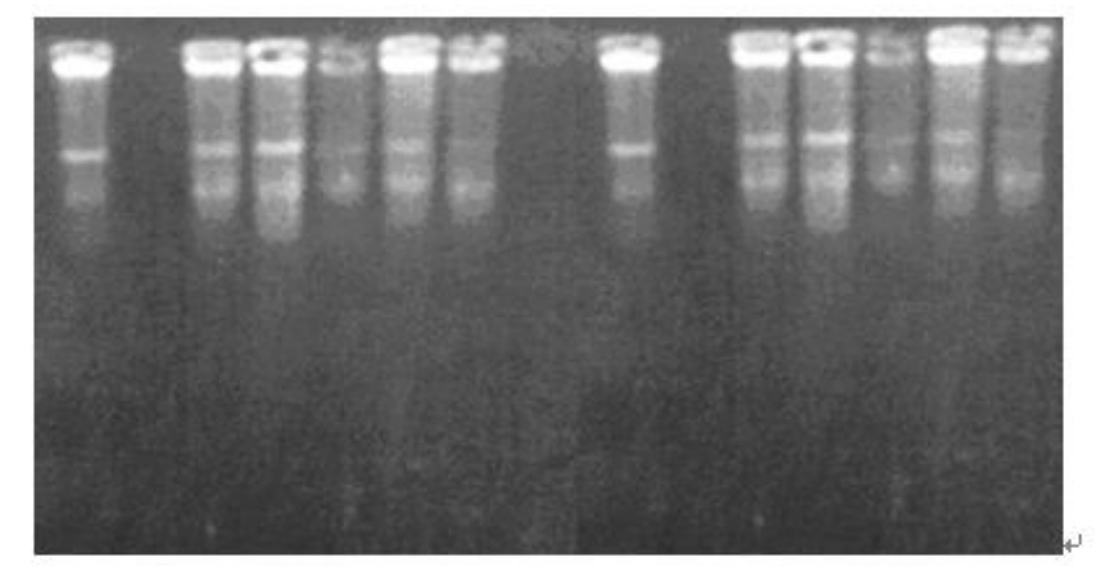

$$
\text { C } \cdots 12 \cdots 3 \cdot 4 \cdot 5 \cdots C \cdot \cdots \cdot 7 \cdot 8 \cdot 9 \cdot 10
$$

Figure 2. Virulence plasmid 70Kbp screening of clinical strains of Yersinia pseudotuberculosis. C. Control, Yersinia enterocolitica. From 1 to 5 Wild types. From 6 to 10 Naledixin mutants.

\subsection{Detection of High Pathogenicity Island of Yersinia Pseudotuberculosis}

Clinical strains of Yersinia pseudotuberculosis harbouring 70KbP plasmid( wild type and Naledixin mutants) were diagnosed for High pathogenicity island(HPI), with PCR, it was found fragments of FyuA and irp2 Figure. $(3,4)$.

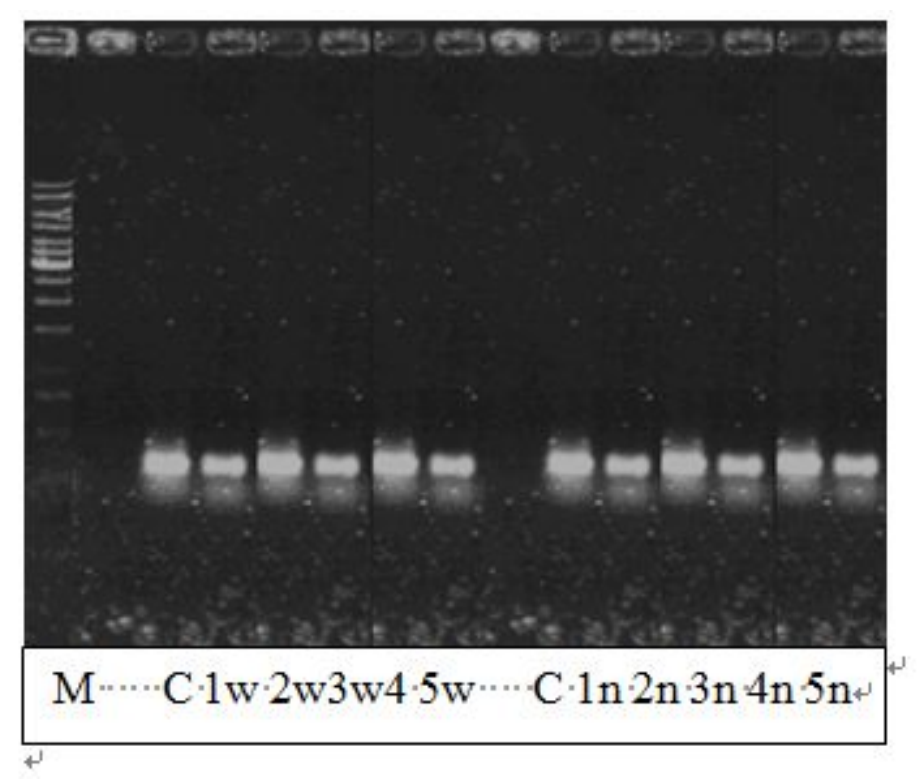

Figure 3. PCR of fyuA gene of clinical strains of Yersinia pseudotuberculosis Where. C control Yersinia enterocolitica 8081-L2, from $1 \mathrm{w}$ to $5 \mathrm{w}$, wild types and from $1 \mathrm{n}$ to $5 \mathrm{n}$ nalidexin mutants. 


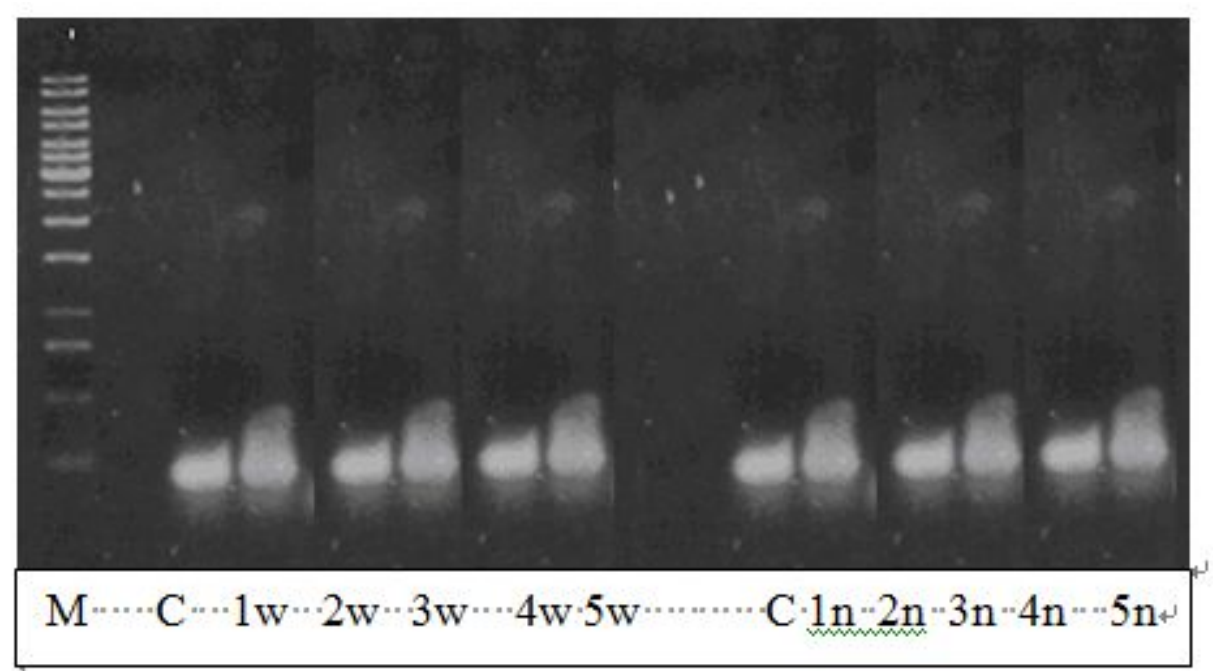

Figure 4. PCR of irp gene of HPI of clinical strains of Yersinia pseudotuberculosis, where M. 1000bp DNA marker, C, control Yersinia enterocolitica 8081-L2.from 1w to 5w , wild types, from $1 \mathrm{n}$ to5n nalidexin mutants.

\subsection{Preservation of 70kbp Virulence Plasmids}

During treatment with naledixin for the plasmid harbouring clinical strains of Yersinia pseudotuberculosis, it was found that strain Yersinia pseudotuberculosis IP395 lost virulence plasmids, but after growth on modified H.B-L.B medium containing naledixine, the virulence plasmid has recovered with additional small plasmids.( Figure.5).

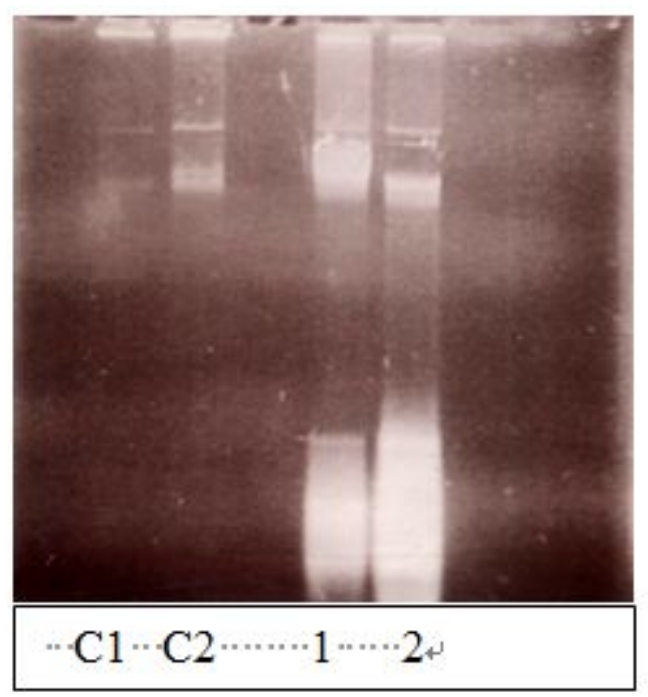

Figure 5. plasmid screening of clinical strain naledixin mutants Yersinia pseudotuberculosis IP3295 after treatment with Human blood H.B-LB medium

C1, control1 Yersinia enterocolitica 8081-L.2, C2, Yersinia pseudotuberculosis IP3295, 1, 2 Yersinia enterocolitica IP3295. 


\section{Discussion}

For most bacterial pathogens virulence is a multifactorial process requiring two general classes of determinants. The first encompasses genes that participate in physiological processes necessary for survival in host and non-host environments and these genes are generally found in both pathogenic and non-pathogenic organisms. The second class of virulence genes specifies traits that are unique to pathogens, and not surprisingly, these genes are rarely detected in non-pathogenic organisms, based on the initial characterization of plasmids from Yersinia and Shigella. Such sequences were originally thought to be confined to extra-chromosomal elements but recently, several virulence cassettes have been mapped to the chromosome of pathogenic organisms. These segments of the chromosome, termed pathogenicity islands (Groisman and Ochman, 1996; Thoerner et al., 2003).

In this study, the detection of virulence plasmid in Yersinia pseudotuberculosis proves the virulence of the different strains of Yersinia pseudotuberculosis. Pathogenic species of Yersinia carry plasmids of about $70 \mathrm{~Kb}$ that appear to be necessary for virulence. These plasmids called pYV plasmids, cause requirement for calcium for growth at $37^{\circ} \mathrm{C}$ pYV-containing Yersiniae from colonies at $28^{\circ} \mathrm{C}$ but not at $37^{\circ} \mathrm{C}$ were grown on media deprived of calcium.

In conditions of growth restriction, i.e. $37^{\circ} \mathrm{C}$ in the absence of calcium, pYV plasmids from $Y$. enterocolitica and $Y$. pseudotuberculosis direct the secretion of at least nine proteins. Some of these proteins are also inserted in the outer membrane, which explain why these proteins are currently referred to as YOPs, for Yersinia outer membrane proteins. The structural genes of these proteins (YOP genes) are scattered around the pYV plasimds (Heesemann et al., 1984; Biot and Cornelis, 1988).

Recent studies showed that the virulence of Y.pseudotuberculosis depends on the pYV plasmid, which is responsible for invasion into epithelial cells in vitro and facilitation of the translocation of bacteria across the intestinal epithelium. Therefore, $Y$. pseudotuberculosis is similar to $Y$. enterocolitica and $Y$. pestis. This loss of plasmid pYV always correlates with the loss of pathogenicity, however, reported that chromosomal genes also prompt in vivo the replication of $Y$. pseudotuberculosis, although the loss of plasmid pYV is associated with a significant decrease in the level of virulence (Fukushima et al., 1991).

This study dealt with one of the important virulence determinants, which is detected in the $Y$. pseudotuberculosis called high pathogenicity island (HPI).

Survival and proliferation within the host depends on the ability of a pathogen to scavenge essential nutrients such as iron, which is bound by the host molecules ferritin, transferrin, and lactoferrin. Bacteria have developed an efficient strategy to obtain iron from these eukaryotic iron scavengers. They produce and secrete low-molecular-weight siderophores with extremely high affinities for ferric iron. The siderophore was designated Yersiniabactin (Ybt). Ybt displays relatively weak iron binding under in vitro culture conditions. Nevertheless, the siderophore activity was detected only in highly pathogenic Yersiniae that are lethal for mice at low infectious doses, (Y. pestis, Y. pseudotuberculosis and Y. enterocolitica).

The yersiniabactin gene cluster responsible for the manifestation of lethality for mice was 
named the high-pathogenicity island (HPI). The complete structure of HPI and the functional core of the island consist of 12 genes. At least six genes encoding Iron-Responsible proteins (Irp1 to Irp5 and Irp9) in Y. enterocolitica (Ybt E and Ybt T are Y. pestis bacteriocin pesticin. Therefore, loss of pesticin sensitivity correlates with loss of the yersiniabactin binding site and with inability of Yersinia to obtain sufficient iron for growth in the mammalian host environment (Heesemann, 1987; Koczura and Kazonwski, 2003; Mokracka et al., 2004).

The fyuA-irp gene cluster identified primarily in yersiniae meets the basic criteria of so called pathogenecity islands, such as (i) a typical $\mathrm{G}+\mathrm{C}$ content on the $45-\mathrm{kbp}$ chromosomal DNA region, (ii) requiring a cluster of genes for virulence, (iii) the presence of mobility genes (eg, insertion elements) as well as association with a tRNA gene at one boundary, and (iv) instability. Moreover, we recently demonstrated that the fyuA-irp gene cluster comprised two evolutionary lineages, one assigned to $Y$. enterocolitica biotype 1B strains and other $Y$. pestis and $Y$. pseudotuberculosis. Surprisingly, the fyuA gene cluster of the latter lineage could also be detected in four pesticin-sensitive E.coli strains indicating that it might be transmissible. Therefore, we investigated the distribution of the fyua-irp gene cluster among some pathogenic species of the family Enterobacteriaceae..

In this study, modification of L.B medium with addition of human blood agar, has returned back the fitness of human pathogenic Yeresinia pseudotuberculosis, to express virulence factors, and recovery of large plasmids, is an indication that human blood is a real environment for pathogens, which could be a substitute of mouse passage in the molecular biology of pathogens work. Moreover recovery of plasmids, proves that plasmids have not kicked out of the bacterial cells but incorporated into the chromosomal DNA, with more additional small plasmids, supports the relatedness of Yersinia pseudotuberculosis and Yersinia pestis.

Genetic relatedness was studied by Kim et al using $16 \mathrm{~S}$ rDNA for the identification of Y.pseudotuberculosis. A phylogenetic tree constructed from $16 \mathrm{~S}$ proved the relatedness of Yersinia pestis and Yersinia pseudotuberculosis..(Kim et al, 2003).

Similarity between Yersinia pestis, the etiological agent of bubonic plague, and entero-pathogenic Yersinia pseudotuberculosis and Yersinia pestis possess three plasmids, of which one shared by the enteropathogenic species, mediates a number of virulence factors that directly or promote survival within macrophages and immunosupression. The two remaining plasmids are unique and encode functions that promote acute disease by enhancing bacterial dissemination in tisuues and resistance to phagocytosis by neutrophils. (Brubaker, 1991). It would be recommended more studies should be done using the modified H.B-L.B medium for inhancement of virulence factors of antibiotic-resistant human pathogens, to give a real and clear picture about the reality and phylogeny of the pathogen.

\section{References}

Brubaker, R. R. (1991). Factors promoting acute and chronic diseases caused by Yersiniae. Clinical microbiology reviews, 309-324.

Cornelis, G. R., Sory, M. P., Iaroche, Y. \& Derelaye, I. O.. Genetic analysis of the plasmid region controlling virulence in Yersinia enterocolitica O:9 by Mini-Mu insertions and lac gene 
fusions. Microb. Pathog, 1, 349-359. http://dx.doi.org/10.1083/jcb.200205077

Cornelis, S. G. R. (2002). Yersinia type II secretion: send in the effectors. J. Cell Biol, 158(3), 401-8.

Denecker, G., Totemeyer, S., Mota, L. J., Troisfontanies, P., Lambermont, I., Youta, C., Stainier, I., Kermann, M. \& Cornelis, G. R. (2002). Effect of low-and high-virulence Yesinia enterocolitica strains on the inflammatory response of human umbilical vein endothelial cells. Infect. Immun, 70(7), 3510-20. http://dx.doi.org/10.1128/IAI.70.7.3510-3520.2002

Fukushima, H., Sato, T., Nagasako, R. \& Takeda, I. (1991). Acute Mesentric lymphadenitis due to Yersinia pseudotuberculosis laking a virulence plasmid. J. Clinical Microbiology, 126-1275.

Fukushima, H., Hao, Q., Wu, K., Hu, X., Chen, J., Guo, Z., Dai, H., Quin, C., Lu, S. \& Gomyoda, M. (2001). Yersinia enterocolitica O:9 as a possible barrier against Yersinia pestis in natural plague foci in Ningxia, China. Curr. Microbial,42 (1), 1-7. http://dx.doi.org/10.1007/s002840010168

Groisman, E. A. \& Ochman, H. (1996). Pathogenecity Islands: Bacterial evolution in Quantum Leaps. Cell, 87,791-794. http://dx.doi.org/10.1016/S0092-8674(00)81985-6

Hayashidani, H., Kanzaki, N., Kaneko, Y., Okatani, A. T., Taniguchi, K. K. \& Ogawa, M. (2002). Occurrence of Yersiniosis and Listeriosis in wild boars in Japan. J. Wild. Dis, 38 (1), $202-5$.

Heesemann, J., Algermissen, B. \& Laufs, R. (1984). Genetically manipulated virulence of Yersinia enterocolitica. Infection and Immunity, 46, 105-110.

Heesemann, J. (1987). Chromosomal-encoded siderophores are required for mouse virulence of enteropathogenic Yersinia species. FEMS. Microbial Lett, 48, 229-233. http://dx.doi.org/10.1111/j.1574-6968.1987.tb02547.x

Hassan, A. S. (2000). Plague: Updated clinical epidemiological and immunological aspects. M. Sc. Thesis. Faculty of Medicine, Cairo University.

Juris, S. J., Shao, F. \& Dixon, J. E. (2002). Yersinia effectors target mammalian signaling pathways. Cell Microbiol, 4(4), 201-11. http://dx.doi.org/10.1046/j.1462-5822.2002.00182.x

Kim,W., Song, M. O, Song, W, Kim, K. J, Chung, S. I, Choi, C. S \& Park, Y. H. (2003). Comparison of $16 \mathrm{~S}$ rDNA analysis and rep-PCR genomic fingerprinting for molecular identification of Yersinia pseudotuberculosis, 83(2), 125-33.

Kaper, J. B. \& Hacker, J. (1999). Pathogenicity Island and other mobile virulence elements. American society for microbiology,77-88.

Maniatis, T., Fritsch, E. F. Sambrook, J. (1982). Molecular cloning, a laboratory Manual. Cold Spring Harbor Laboratory, 149-171.

Mingrone, M. G. \& Fantasia, M. (1988). Characteristics of Yersinia spp. isolated from wild and zoo animals. J. Wild. Dis. 24(1), 25-9. 


\section{Macrothink}

Mokracka, J., koczura, R. \& Kaznowski, A. (2004). Yersiniabactin and other siderophores produced by clinical isolates of Enterobacter spp and Citrobacter spp. FEMS. Immunol Med Microbiol, 15, 40.

Thoerner, P., Bin, K. C. I., Boglidtuber., Bissig-Choisat, B., Wassenaar, T. M., Frey, J. \& Jemmi, T. (2003). PCR detection of virulence genes in Yersinia enterocolitica and Yersinia pseudotuberculosis and investigation of virulence gene distribution. Appl. Environ Microbiol, 69(3), 1810-6. http://dx.doi.org/10.1128/AEM.69.3.1810-1816.2003

\section{Copyright Disclaimer}

Copyright reserved by the author(s).

This article is an open-access article distributed under the terms and conditions of the Creative Commons Attribution license (http://creativecommons.org/licenses/by/3.0/). 